\title{
Influence of High Temperature and Reduced Irradiance on Glycoalkaloid Levels in Potato Leaves
}

\author{
Abbas M. Lafta and James H. Lorenzen ${ }^{1}$ \\ Department of Plant Sciences, North Dakota State University, Fargo ND 58105
}

\begin{abstract}
AdDitional INDEX words. $\alpha$-chaconine, $\alpha$-solanine, leptine I, leptine II, Solanum tuberosum, Colorado potato beetle, Leptinotarsa decemlineata
\end{abstract}

\begin{abstract}
Aвstract. Growth chamber and greenhouse experiments were conducted to investigate the effect of temperature and irradiance on foliar glycoalkaloids of three potato genotypes (Solanum tuberosum $\mathrm{L}$.) that differ in glycoalkaloid content. Two genotypes (ND4382-17 and ND4382-19) produced the acetylated glycoalkaloids, leptine I and II, that contribute resistance to the Colorado potato beetle (CPB, Leptinotarsa decemlineata Say). The glycoalkaloids were separated and quantified by high performance liquid chromatography. Exposure of plants to high temperature $\left(32 / 27^{\circ} \mathrm{C}\right.$, 14-hour day/10-hour night) for 3 weeks under a 14-hour photoperiod with an irradiance of $475 \mu \mathrm{mol} \cdot \mathrm{m}^{-2} \cdot \mathrm{s}^{-1}$ significantly increased the levels of leptines I and II, solanine, and chaconine compared to that at low temperature $\left(22 / 17^{\circ} \mathrm{C}\right)$. Increases in foliar leptines and total glycoalkaloids at high temperature were $90 \%$ and $169 \%$, respectively. Growing potato plants at low irradiance $(75 \%$ reduction) for 2 or 4 weeks resulted in a significant reduction in the levels of leptine I and II (46\%), solanine (43\%), and chaconine $(38 \%)$ compared to nonshaded plants. Transferring plants from high to low irradiance or from low to high irradiance for 2 weeks caused a decrease and an increase in glycoalkaloid concentration, respectively. Therefore, both temperature and irradiance influenced foliar levels of glycoalkaloids in potato plants without changing the leptines and solanine to chaconine ratios. Thus, irradiance and temperature influenced glycoalkaloid compounds that can effect resistance to $\mathrm{CPB}$, especially leptine I and II.
\end{abstract}

Control of the Colorado potato beetle (CPB; Leptinotarsa decemlineata), a serious pest of potato, with insecticides has become increasingly difficult as this insect has developed resistance to various compounds (Forgash, 1985; Grafius, 1997; Hare, 1990; Roush and Tingey, 1994). Development of CPB resistant potato cultivars is a promising pest management strategy that may complement other forms of biological control. One mechanism of natural resistance to CPB is the presence of specific glycoalkaloids in the foliage (Sanford et al., 1996; Sikinyi et al., 1997; Sinden et al., 1986a; Sturckow and Löw, 1961). Glycoalkaloids are a naturally occurring group of steroidal glycosides found in the Solanaceae (Friedman and McDonald, 1997; Maga, 1994) some of which are deterrent factors to CPB (Tingey 1984). The foliar glycoalkaloids that contribute resistance to $\mathrm{CPB}$ are leptines, acetylated forms of the common potato glycoalkaloids, chaconine and solanine (Kuhn and Löw, 1961; Sanford et al., 1998; Sinden et al., 1986a).

Environmental conditions can influence foliar glycoalkaloid levels and alter plant resistance to insects, such as CPB. Deahl et al. (1991) studied the effect of irradiance on the concentration of foliar leptines and survival of CPB larvae. They found that a reduction in larval development rate and increased larval mortality was related to the higher concentrations of foliar leptines produced at higher irradiance. Tuber glycoalkaloids are also increased upon exposure to light (Baerug, 1962; Gull and Isenberg, 1960; Percival et al., 1996).

Temperature is an environmental factor that may affect the concentration of glycoalkaloids in potato plants. Considerable information has been published on the effect of storage temperature on glycoalkaloids in potato tubers (Edwards and Cobb, 1997; Griffiths et al., 1994, 1997; Maga, 1994). Summer-grown potato tubers in a subtropical Mediterranean climate had higher steroid glycoalkaloids than spring or winter-grown tubers (Dimenstein et

Received for publication 20 July 1999. Accepted for publication 13 Apr. 2000. The cost of publishing this paper was defrayed in part by the payment of page charges. Under postal regulations, this paper therefore must be hereby marked advertisement solely to indicate this fact.

${ }^{1}$ Corresponding author. al., 1997). However, there is no information available on the effect of high temperature on foliar glycoalkaloid content, especially the acetylated glycoalkaloids leptine I and II. Therefore, the following study was conducted to determine the influence of high temperature and irradiance on glycoalkaloid content of potato leaves, including genotypes that produce leptine I and II. Such information will enhance our understanding of the effect of environmental conditions on plant resistance to the CPB.

\section{Materials and Methods}

Plant material. Plants of the leptine-producing genotypes, ND4382-17 and ND4382-19, from the North Dakota State University breeding program and the potato cultivars Norchip and NorValley were micropropagated from single-node cuttings in MS medium (Murashige and Skoog, 1962) and transferred to 2.3-L pots filled with a peat-vermiculite medium (Sunshine Mix 1, Fisons Hort., Bellevue, Wash.). Plants were transferred to a greenhouse for the irradiance experiment and to controlled-environment chambers for the temperature experiment. Plants in both experiments were fertigated daily or as needed with a $15 \mathrm{~N}-7 \mathrm{P}-14 \mathrm{~K}$ water-soluble fertilizer (Peters, Forgelsvile, Pa.) at $1 \mathrm{~g} \cdot \mathrm{L}^{-1}$.

TeMPERATURE EXPERIMENT. Controlled-environment chambers (model PT-80; Percival Mfg. Co., Boone, Iowa) that provided an irradiance of $475 \mu \mathrm{mol} \cdot \mathrm{m}^{-2} \cdot \mathrm{s}^{-1}$ (from cool-white fluorescent lamps supplemented with incandescent light) were used in this experiment. The irradiance was measured at canopy level with a quantum/ radiometer/photometer (LI-185; LI-COR, Inc., Lincoln, Nebr.). Plants of ND4382-17, ND4382-19, and 'Norchip' were maintained initially for 3 weeks at 14 -h days $/ 10$-h nights of $22 / 17^{\circ} \mathrm{C}$ with a $14-$ $\mathrm{h}$ photoperiod. Half of the plants were then transferred to high temperature $\left(32 / 27^{\circ} \mathrm{C}\right.$ days/nights) for 3 weeks with a 14-h photoperiod. High temperature treatment was imposed when plants had about eight leaves. Relative humidity was maintained at $50 \%$ in the $22 / 17^{\circ} \mathrm{C}$ chamber and at $70 \%$ in the $32 / 27^{\circ} \mathrm{C}$ chamber. Plants exposed to high temperature were watered frequently to minimize water stress. Samples for glycoalkaloid analysis were taken from 




Fig. 1. Glycoalkaloid levels in potato leaves after 3 weeks of low or high temperature treatment. Each data point represents the mean of 12 composite samples from three genotypes. Lept I, Lept II, Sol, Chac, and TGA represent leptine I, leptine II, solanine, chaconine, and total glycoalkaloids, respectively. Vertical bars $=\mathrm{SE}$.

leaf number 7 and 8 from the top of the plant after 3 weeks of heat treatment. Samples were frozen in liquid nitrogen and stored at -70 ${ }^{\circ} \mathrm{C}$, lyophilized, and pulverized for analysis. The experimental design was a randomized complete block design with four replications of two plants per genotype.

IRRADIANCE EXPERIMENT. This experiment was conducted in July 1997 in a greenhouse with two irradiance levels. The low level was created by shading the plants with mesh cloth that reduced irradiance by $75 \%$ of the nonshaded level of $\approx 900 \mu \mathrm{mol} \cdot \mathrm{m}^{-2} \cdot \mathrm{s}^{-1}$ at midday. The differential light treatment was imposed when plants had about eight expanded leaves. The natural photoperiod in the greenhouse was $16 \mathrm{~h}$ and the average 16-h day/8-h night temperature was 24/16 ${ }^{\circ} \mathrm{C}$. The commercial potato cultivar NorValley and two high leptine clones (ND4382-17 and ND4382-19) were used in this experiment. Leaf samples were taken for glycoalkaloid analysis after 2 and 4 weeks of light treatment and processed as above. The experimental design was a randomized complete block design with three replications of two plants per genotype. The effect of shifting light conditions on glycoalkaloids was studied using ND4382-17 only. Plants were grown at high and low irradiance for 2 weeks then half the plants were transferred from high irradiance to low irradiance and from low irradiance to high irradiance and maintained for an additional 2 weeks at these conditions. Samples for glycoalkaloids were taken after 1, 2, and 4 weeks of light treatments.

GLYCOALKALOIDEXTRACTION AND ANALYSIS. Glycoalkaloids were extracted from ground, lyophilized leaf samples $(100 \mathrm{mg})$ with $8 \mathrm{~mL}$ of an extraction reagent containing $4 \mathrm{~g}$ 1-heptanesulfonic acid and $10 \mathrm{~mL}$ of glacial acetic acid in $1 \mathrm{~L}$ of water (Carman et al., 1986). The extract was cleaned with a $\mathrm{C}_{18}$ (Jones Chromatography, Lakewood, Colo.) solid phase extraction column $(5 \mathrm{~mL})$. The columns were preconditioned with $100 \%$ methanol, followed by the extraction reagent before applying the sample. Samples were washed with $20 \%$ acetonitrile, after which the glycoalkaloids were eluted with 2 $\mathrm{mL}$ of the high-performance liquid chromatography (HPLC) mobile phase. The mobile phase consisted of $50 \%$ acetonitrile, $0.94 \mathrm{~g}$ 1-heptanesulfonic acid, and $5 \mathrm{~mL}$ of $0.033 \mathrm{~mol} \cdot \mathrm{L}^{-1}$ phosphoric acid in $1 \mathrm{~L}$ of water. The glycoalkaloids were separated and quantified by HPLC using a Resolve $\mathrm{C}_{18} 3.9 \times 300 \mathrm{~mm}$ HPLC column from Waters, Milford, Mass. (Sinden et al., 1986b). The flow rate was
$0.55 \mathrm{~mL} \cdot \mathrm{min}^{-1}$ and the detection was by ultra violet light at $205 \mathrm{~nm}$. Data were analyzed for a randomized complete block design using the microcomputer package MSTAT (Michigan State Univ., East Lansing). Analysis of variance and LSD procedures at $P \leq 0.05$ were used for mean separation.

\section{Results}

Four individual glycoalkaloids were identified and quantified by HPLC as leptine I, leptine II, solanine, and chaconine. Leptines were detected in the foliage of ND4382-17 and ND4382-19 but not in the foliage of the commercial cultivars Norchip and NorValley.

Temperature EFFects. The effect of temperature on foliar glycoalkaloids is illustrated in Fig. 1. Exposure of potato plants to high temperature for 3 weeks resulted in a significant increase in the concentrations of leptine I and II, solanine, chaconine, and total glycoalkaloids. The increase in leptine I and II, solanine, chaconine, and total glycoalkaloids was $109 \%, 61 \%, 238 \%, 160 \%$, and $169 \%$, respectively. There were no significant temperature $\times$ genotype interactions for solanine, chaconine or total glycoalkaloids concentrations. The significant temperature $\times$ genotype interaction with regard to leptine I and total leptines is not presented because it reflects the fact that 'Norchip' does not produce leptines. The level of foliar glycoalkaloids was higher in ND 4382-17 [13.4 $\mathrm{mg} \cdot \mathrm{g}^{-1} \mathrm{dry}$ weight (DW)] than in ND4382-19 $\left(8.7 \mathrm{mg} \cdot \mathrm{g}^{-1} \mathrm{DW}\right)$ and Norchip $\left(7.7 \mathrm{mg} \cdot \mathrm{g}^{-1} \mathrm{DW}\right)$ at both temperatures.

IRRADIANCE EFFECTS. The effect of irradiance after 2 weeks on foliar glycoalkaloids is illustrated in Fig. 2. Exposing potato plants to low irradiance for 2 weeks significantly reduced all glycoalkaloids compared to plants grown at normal high irradiance. The reduction in leptine I and II, solanine, chaconine, and total glycoalkaloids was $42 \%, 51 \%, 43 \%, 38 \%$, and $42 \%$, respectively. There was no significant interaction between irradiance and genotypes on glycoalkaloid levels. Levels of leptines and total glycoalkaloids remained nearly constant as plants were held for an additional 2 weeks at the respective light levels (Fig. 3). However, when a subset of the plants was transferred to the alternate light regime, concentrations of leptine and total glycoalkaloids in plants transferred to the shaded regime were reduced to the level of plants that had continu-

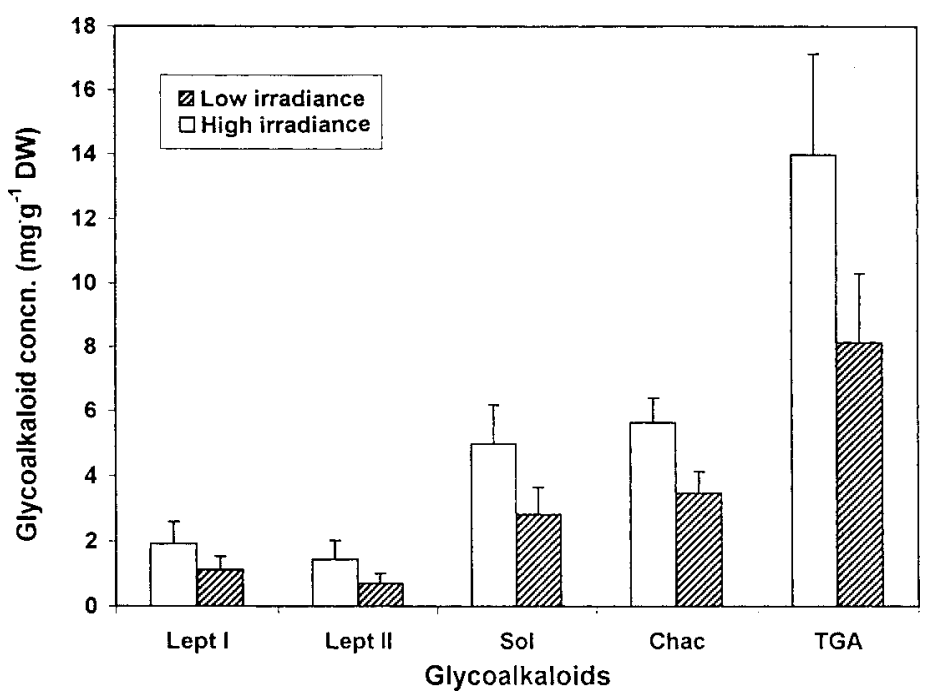

Fig. 2. Glycoalkaloid levels in potato leaves after 2 weeks of low or high irradiance. Each data point represents the mean of nine composite samples from three genotypes. Lept I, Lept II, Sol, Chac, and TGA represent leptine I, leptine II, solanine, chaconine, and total glycoalkaloids, respectively. Vertical bars $=\mathrm{SE}$. 


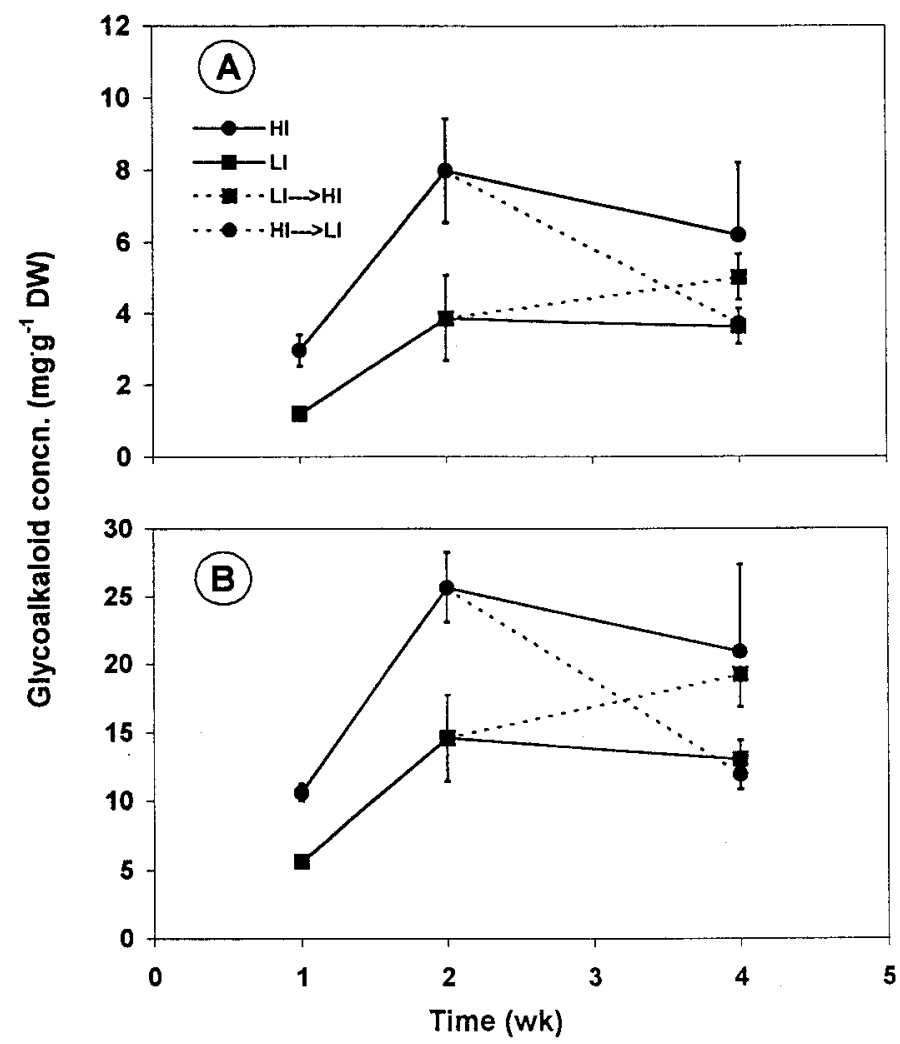

Fig. 3. Effect of shifting light conditions on (A) total leptines and (B) total glycoalkaloids in potato leaves. Leaf samples were taken from ND4382-17 after 1,2 or 4 weeks of light treatment. Data represent the mean of three replications. $\mathrm{HI}$ and LI represent high and low irradiance, respectively. Vertical bars $=\mathrm{SE}$.

ous low irradiance (Fig. 3), while leptine and total glycoalkaloid content of shaded plants returned to full light was nearly restored to that of plants continuously held at full light (Fig. 3). The level of total glycoalkaloids varied little with stage of development. Total glycoalkaloids in young, recently mature, and mature leaves of ND4382-17 grown for 6 weeks in the greenhouse were 17.5, 16.8, and $17.6 \mathrm{mg} \cdot \mathrm{g}^{-1} \mathrm{DW}$, respectively.

\section{Discussion}

The genotypes utilized in this study were selected based on presence or absence of leptine I and II, the acetylated forms of glycoalkaloid chaconine and solanine, in their foliage. Leptines are considered deterrent factors to CPB (Kuhn and Löw, 1961; Sanford et al., 1998; Sinden et al., 1986a). ND4382-17 and ND4382-19 produce leptine. However, the commercial cultivars, Norchip and NorValley, do not produce leptine and no leptines were detected in their foliage in either experiment.

TeMPerature EFFECTs. Growing potato plants for 3 weeks at 32/ $27{ }^{\circ} \mathrm{C}$ resulted in a significant increase in foliar glycoalkaloids compared to plants grown at $22 / 17^{\circ} \mathrm{C}$ (Fig. 2). All genotypes had similar increases in solanine and chaconine, and the two leptineproducing genotypes had similar increases in leptines at the higher temperature. There was a $90 \%$ increase in total leptines when plants were exposed to high temperature for 3 weeks. This increase in leptines at high temperature could affect resistance to CPB, since leptines are an important resistance factor (Deahl et al., 1991; Sinden etal., 1986a). The effect of hightemperature on glycoalkaloids, especially leptine I and II, has not been reported previously.
IRRADIANCE EFFECTS. Exposure of potato plants to low irradiance for 2 or 4 weeks caused a reduction in the overall concentration of glycoalkaloids. The levels of leptines and total glycoalkaloids in shaded leaves after 2 weeks were reduced by $46 \%$ and $42 \%$ from those at high irradiance. This indicated a significant effect of irradiance on foliar glycoalkaloids. These results are consistent with those of Deahl et al. (1991) who reported that levels of foliar leptines and total glycoalkaloids at low irradiance were less than those at high irradiance by $60 \%$ and $69 \%$, respectively. The high level of foliar leptines at high irradiance was detrimental to growth and development of CPB larvae (Deahl et al., 1991). The effect of light on glycoalkaloids was reversible, as plants transferred from low to high irradiance quickly developed the glycoalkaloid content of plants maintained at that level and vice versa. Therefore, the responsiveness of foliar glycoalkaloids to the environment is maintained in developed leaves in a bidirectional manner, showing that leaves maintain dynamic control over glycoalkaloid levels throughout development. Conditions that increase the levels of leptines at high irradiance could enhance resistance to $\mathrm{CPB}$. We have observed that host-plant effects on CPB larval development were diminished when plants were grown in controlled-environment chambers with insufficient light, or in the greenhouse in the winter compared to spring-grown plants or field plants in the summer (unpublished data). Infiltration of leaf disks with leptine I at $100 \mathrm{mg} / 100 \mathrm{~g}$ fresh weight (FW) inhibited Colorado potato beetle feeding (Sturckow and Löw, 1961). Sinden et al. (1986a) found a reduction in weight gain of larvae reared on excised leaves from high leptine $(55,143$, and $222 \mathrm{mg} / 100 \mathrm{~g} \mathrm{FW}$ ) genotypes compared to the control.

The level of glycoalkaloids in potato tubers can be influenced by environmental factors during the growing season and postharvest treatments. For example, growing plants at low irradiance decreased the glycoalkaloid content of potato tubers (Swaaij, 1993). Postharvest exposure of potato tubers to light increased the level of glycoalkaloids (Gull and Isenberg, 1960; Jain et al., 1995; Percival et al., 1996; Zitnak, 1981). Sinden and Sanford (1981) observed an increase in solamarine in tuber slices of 'Kennebec' and 'USDA9656' upon exposure to light during wound-healing compared to those kept in the dark. The level of solanidine in tubers was higher under long days than under short days, but other steroidal glycoalkaloids such as solasodine and tomatidenol were reduced under long days (Van Gelder and Scheffer, 1991). Griffiths et al. (1997) indicated that the accumulation of glycoalkaloids in potato tubers depends on cultivar and storage temperature.

In addition to temperature and light, other factors can influence glycoalkaloid content in potato plants. Stage of development is one such factor. The level of solamarine was higher in young foliage than in mature or senescent foliage (Sinden and Sanford, 1981), but tomatine levels in tomato leaves (Lycopersicon esculentum Mill) increased with maturity (Sinden et al., 1978). In our study, leaf maturity had little influence on total glycoalkaloid content or the relative amounts of specific glycoalkaloids. Potato tubers harvested while immature, or tubers from plants exposed to environmental conditions that retarded tuber maturity had higher glycoalkaloid content (Sinden and Webb, 1972). Excess nitrogen fertilizer during the growing season (Cronk et al., 1974; Love et al., 1994) and impact damage to potato tubers (Olsson, 1986; Petersen et al., 1993) also increased the level of glycoalkaloid in potato tubers. Thus, environmental conditions during and after the growing season significantly influence the levels of glycoalkaloids in potato plants and tubers.

We conclude that temperature and light levels in the growing environment may influence resistance of potato plants to CPB by affecting levels of foliar leptines. Both high temperature and high 
irradiance stimulated glycoalkaloid accumulation in leaves. Thus, awareness of environmental conditions may be important when screening potato plants for CPB resistance.

\section{Literature Cited}

Baerug, R. 1962. Influence of different rates and intensities of light on solanine content and cooking quality of potato tubers. European Potato J. $5: 242-251$

Carman, A.S., S.S. Kuan, G.M. Ware, O.J. Francis, Jr., and G.P. Kirschenheuter. 1986. Rapid high performance liquid chromatographic determination of the potato glycoalkaloids $\alpha$-solanine and $\alpha$-chaconine. J. Agr. Food Chem. 34:279-282.

Cronk, T.C., G.D. Kuhan, and F.J. McArdle. 1974. The influence of stage of maturity, level of nitrogen fertilization, and storage on the concentration of solanine in tubers of three potato cultivars. Bul. Environ. Contamination Toxicol. 11:163-168.

Deahl, K.L., W.W. Cantelo, S.L. Sinden, and L.L. Sanford. 1991. The effect of light intensity on Colorado potato beetle resistance and foliar glycoalkaloid concentration of four Solanum chacoense clones. Amer. Potato J. 68:659-666.

Dimenstein, L., N. Lisker, N. Kedar, and D. Levy. 1997. Changes in the content of steroidal glycoalkaloids in potato tubers grown in the field and in the greenhouse under different conditions of light, temperature and daylength. Physiol. Mol. Plant Pathol. 50:391-402.

Edwards, E.J. and A.H. Cobb. 1997. Effect of temperature on glycoalkaloid and chlorophyll accumulation in potatoes (Solanum tuberosum L. cv. King Edward) stored at low photon flux density, including preliminary modeling using an artificial neural network. J. Agr. Food Chem. 45:10321038.

Forgash, A.J. 1985. Insecticide resistance in the Colorado potato beetle, p. 33-52. In:D.N. Ferro and R.H. Voss (eds.). Proceeding of the symposium on the Colorado potato beetle. Mass. Agr. Expt. Sta. Bul. 704.

Friedman, M. and G.M. McDonald. 1997. Potato glycoalkaloids: Chemistry, analysis, safety, and plant physiology. Crit. Rev. Plant Sci. 16:55132.

Grafius, E. 1997. Economic impact of insecticide resistance in the Colorado potato beetle (Coleoptera: Chrysomelidae) on the Michigan potato industry. J. Econ. Entomol. 90:1144-1151.

Griffiths, D.W., H. Bain, and M.F.B. Dale. 1997. The effect of lowtemperature storage on the glycoalkaloid content of potato (Solanum tuberosum) tubers. J. Sci. Food Agr. 74:301-307.

Griffiths, D.W., M.F.B. Dale, and H. Bain. 1994. The effect of cultivar, maturity and storage on photo-induced changes in the total glycoalkaloid and chlorophyll contents of potatoes (Solanum tuberosum). Plant Sci. 98:103-109.

Gull, D.D. and F.M. Isenberg. 1960. Chlorophyll and solanine content and distribution in four varieties of potato tubers. Proc. Amer. Soc. Hort. Sci. 75:545-556.

Hare, J.D. 1990. Ecology and management of the Colorado potato beetle. Annu. Rev. Entomol. 35:81-100.

Jain, S., S.L. Shoo, and R. Vijavergia. 1995. Influence of light on growth and production of steroids and glycoalkaloids in Solanum species in vivo and in vitro. Indian J. Pharmaceutical Sci. 57:100-101.

Kuhn, R. and I. Löw. 1961. Zur Konstitution der Leptine. Chem. Ber. 94:1088-1095.

Love, S.L., T.J. Herrman, A. Thompson-Johns, and T.P. Baker. 1994. Effect and interaction of crop management factors on the glycoalkaloid concentration of potato tubers. Potato Res. 37:77-85.

Maga, J.A. 1994. Glycoalkaloids in Solanaceae. Food Rev. Intl. 10:385418.

Murashige, T. and F. Skoog. 1962. A revised medium for rapid growth and bioassays with tobacco tissue cultures. Physiol. Plant. 15:473-497.

Olsson, K. 1986. The influence of genotype on the effects of impact damage on the accumulation of glycoalkaloids in potato tubers. Potato Res. 29:112.

Percival, G.C, G.R. Dixon, and A. Sword. 1996. Glycoalkaloid concentration of potato tubers following exposure to daylight. J. Sci. Food Agr. 71:59-63.

Peterson, H.W., J. Christianson, and S. Nielsen. 1993. Influence of light and mechanical damages on the accumulation of glycoalkaloids in potatoes. Abstr. 12th Triennial Conf., Euro. Assn. Potato Res., Paris, France. p. 159-160.

Roush, R.T. and W.M. Tingey. 1994. Strategies for the management of insect resistance to synthetic and microbial insecticides, p. 237-254. In: G.W. Zehnder, M.L. Powelson, R.K. Jansson, and K.V. Raman (eds.). Advances in potato pest biology and management. APS Press, St. Paul., Minn.

Sanford, L.L., R.S. Kobayashi, K.L. Deahl, and S.L. Sinden. 1996. Segregation of leptines and other glycoalkaloids in Solanum tuberosum (4x) X S. chacoense $(4 \mathrm{x})$ crosses. Amer. Potato J. 73:21-33.

Sanford, L.L., S.P. Kowalski, C.M. Ronning, and K.L. Deahl. 1998. Leptines and other glycoalkaloids in tetraploid Solanum tuberosum X Solanum chacoense $\mathrm{F}_{2}$ hybrid and backcross families. Amer. J. Potato Res. 75:167-172.

Sikinyi, E., D.J. Hannapel, P.M. Imerman, and H.M. Stahr. 1997. Novel mechanism for resistance to Colorado potato beetle (Coleoptera: Chrysomelidae) in wild Solanum species. J. Econ. Entomol. 90:689-696.

Sinden, S.L. and L.L. Sanford. 1981. Origin of inheritance of solamarine glycoalkaloids in commercial potato cultivars. Amer. Potato J. 58:305325.

Sinden, S.L., L.L. Sanford, W.C. Cantelo, and K.L. Deahl. 1986a. Leptine glycoalkaloids and resistance to the Colorado potato beetle (Coleoptera: Chrysomelidae) in Solanum chacoense. Environ. Entomol. 15:10571062.

Sinden, S.L, L.L. Sanford, and K.L. Deahl. 1986b. Segregation of leptine glycoalkaloid in Solanum chacoense Bitter. J. Agr. Food Chem. 34:372377.

Sinden, S.L., J.M. Schalk, and A.K. Stoner. 1978. Effects of day length and maturity of tomato plants on tomatine content and resistance to the Colorado potato beetle. J. Amer. Soc. Hort. Sci. 103:596-600.

Sinden, S.L. and R.E. Webb. 1972. Effect of variety and location on the glycoalkaloid content of potatoes. Amer. Potato J. 49:334-338.

Sturckow, B. and I. Löw. 1961. Die Wirkung einiger Solanumalkaloidglykoside auf den Kartoffelkafer, Leptinotarsa decemlineata Say. Entomol. Expt. Et Appl. 4:133-142.

Swaaij, N.V.1993. Influence of some growth conditions on the glycoalkaloid content in potatoes. Abstr. 12th Triennial Conf., Euro. Assn. Potato Res., Paris, France. p. 194-195.

Tingey, W.M. 1984. Glycoalkaloids as pest resistance factors. Amer. Potato J. 61:157-167.

Van Gelder, W.M.J. and J.J.C. Scheffer. 1991. Transmission of steroidal glycoalkaloids from Solanum vernei to the cultivated potato. Phytochemistry 30:165-168.

Zitnak, A. 1981. Photoinduction of glycoalkaloids in cured potatoes. Amer. Potato J. 58:415-421. 